\title{
Bradykinin Enhances AMPA and NMDA Receptor Activity in Spinal Cord Dorsal Horn Neurons by Activating Multiple Kinases to Produce Pain Hypersensitivity
}

\author{
Tatsuro Kohno, ${ }^{1,2 \star}$ Haibin Wang, ${ }^{1 \star}$ Fumimasa Amaya, ${ }^{1}$ Gary J. Brenner, ${ }^{1}$ Jen-Kun Cheng, ${ }^{3}$ Ru-Rong Ji, ${ }^{3}$ and \\ Clifford J. Woolf ${ }^{1}$ \\ ${ }^{1}$ Neural Plasticity Research Group, Department of Anesthesia and Critical Care, Massachusetts General Hospital and Harvard Medical School, Charlestown, \\ Massachusetts 02129, ${ }^{2}$ Division of Anesthesiology, Niigata University Graduate School of Medical and Dental Sciences, Niigata 951-8510, Japan, and ${ }^{3}$ Pain \\ Research Center, Department of Anesthesia, Brigham and Women’s Hospital and Harvard Medical School, Boston, Massachusetts 02115
}

\begin{abstract}
Bradykinin potentiates synaptic glutamate release and action in the spinal cord via presynaptic and postsynaptic $B_{2}$ receptors, contributing thereby to activity-dependent central sensitization and pain hypersensitivity (Wang et al., 2005). We have now examined the signaling pathways that are responsible for the postsynaptic modulatory actions of bradykinin on glutamatergic action and transmission in superficial dorsal horn neurons. $\mathrm{B}_{2}$ receptors are coexpressed in dorsal horn neurons with protein kinase $\mathrm{A}(\mathrm{PKA})$ and the $\delta$ isoform of protein kinase $\mathrm{C}(\mathrm{PKC})$, and we find that the augmentation by bradykinin of AMPA and NMDA receptor-mediated currents in lamina II neurons requires coactivation of both PKC and PKA. The activation of PKA is downstream of COX1 (cyclooxygenase-1). Extracellular signal-regulated kinase (ERK) activation is involved after the PKC and PKA coactivation, and intrathecal administration of bradykinin induces a thermal hyperalgesia in vivo, which is reduced by inhibition of ERK, PKA, and PKC. We conclude that bradykinin, by activating multiple kinases in dorsal horn neurons, potentiates glutamatergic synaptic transmission to produce pain hypersensitivity.
\end{abstract}

Key words: bradykinin; spinal cord; pain; glutamate; neuromodulator; signal transduction

\section{Introduction}

The sensory inflow carried by nociceptors induces an activitydependent increase in synaptic efficacy in dorsal horn neurons, central sensitization, which contributes to pain hypersensitivity (Woolf, 1983; Cook et al., 1987; Simone et al., 1991). Central sensitization results from alterations in ionotropic NMDA and AMPA glutamate receptors that are attributable both to the trafficking of intracytoplasmic receptors to the membrane and to phosphorylation-mediated alterations in receptor/ion channel function (Woolf and Salter, 2000). Multiple factors acting presynaptically and postsynaptically can induce central sensitization. These include glutamate itself acting on NMDA, mGluR, and AMPA receptors; substance P acting on NK1 receptors; BDNF acting on TrkB receptors; and $\mathrm{PGE}_{2}$ acting on $\mathrm{EP}$ receptors (Ji et al., 2003). These ligand-gated ion channels, GPCRs, and receptor tyrosine kinases activate intracellular signaling pathways in dorsal horn neurons that include PKC, CaM kinase, Src, and ERK, to increase synaptic efficacy and produce homosynaptic

\footnotetext{
Received July 30, 2007; revised Feb. 28, 2008; accepted March 19, 2008.

This work was supported by National Institutes of Health Grants NS039518 (C.J.W.) and NS054932 (R.-R.J.).

*T.K. and H.W. contributed equally to this work.

Correspondence should be addressed to Dr. Clifford J. Woolf, Neural Plasticity Research Group, Department of Anesthesia and Critical Care, Massachusetts General Hospital and Harvard Medical School, Charlestown, MA 02129 E-mail: cwoolf@partners.org.

DOI:10.1523/JNEUROSCI.5349-07.2008

Copyright $\odot 2008$ Society for Neuroscience $\quad$ 0270-6474/08/284533-08\$15.00/0
}

and heterosynaptic facilitation (Ji et al., 1999, 2003; Kawasaki et al., 2004).

Bradykinin (BK), a peripherally acting inflammatory mediator that has a major role in producing peripheral sensitization in response to peripheral inflammation (Couture et al., 2001; Wang et al., 2006), also plays a role in pain transmission in the CNS (Chapman and Dickenson, 1992; Ferreira et al., 2002; Wang et al., 2005). In a previous study, we demonstrated that the $B_{2}$ receptor, for which bradykinin is the natural ligand, is expressed by dorsal root ganglion and dorsal horn neurons and that $\mathrm{B}_{2}$-selective agonists potentiate glutamatergic synaptic transmission by increasing glutamate's release and postsynaptic actions (Wang et al., 2005). We found, moreover, that activity-dependent central sensitization and pain hypersensitivity are significantly diminished by intrathecal delivery of a $B_{2}$ antagonist and in $B_{2}$ receptor knock-out mice.

What signaling mechanisms in dorsal horn neurons may underlie the postsynaptic enhancement of AMPA and NMDA receptor-mediated currents by bradykinin to enhance pain sensitivity? $\mathrm{B}_{2}$ receptors act mainly through $\mathrm{G} \alpha_{\mathrm{q}}$ and to a more limited extent also $\mathrm{G} \alpha_{\mathrm{i}}$ (Prado et al., 2002). $\mathrm{G} \alpha_{\mathrm{q}}$ coupling stimulates phospholipase $\mathrm{C}_{\beta}\left(\mathrm{PLC}_{\beta}\right)$ and phospholipase $\mathrm{A}_{2}\left(\mathrm{PLA}_{2}\right)$ (Prado et al., 2002). PLC ${ }_{\beta}$ activates PKC via diacyl glycerol (DAG) and microsomal $\mathrm{Ca}^{2+}$ release. $\mathrm{PLA}_{2}$ triggers the release of arachidonic acid, which when converted by cyclooxygenases (Cox) and prostaglandin synthases to $\mathrm{PGE}_{2}$, can, via EP GPCR receptors, activate PKA (Smith et al., 2000). PKA and PKC, by directly or 
indirectly phosphorylating NMDA or AMPA receptor subunits (Yu et al., 1997; Esteban et al., 2003), alter their trafficking to the membrane and kinetic properties (voltage-dependent block, channel open time, burst behavior), increasing synaptic efficacy (Carroll and Zukin, 2002; Song and Huganir, 2002). In this study, we have examined the signaling mechanisms responsible for bradykinin's central effects on dorsal horn neurons and show that the kinin appears to require coactivation of PKA and PKC followed by ERK activation to augment glutamate responsiveness.

\section{Materials and Methods}

Spinal cord slice preparation and whole-cell patch-clamp recording. Transverse lumbar spinal cord slices $(\sim 600 \mu \mathrm{m})$ with an attached dorsal root were prepared from terminally anesthetized adult (5-8 weeks) Sprague Dawley rats (Charles River Laboratories, Wilmington, MA) with a vibrating microslicer (DTK 1500; Dosaka, Kyoto, Japan) and perfused in oxygen-bubbled Krebs' solution (in mM: $117 \mathrm{NaCl}, 3.6 \mathrm{KCl}, 2.5 \mathrm{CaCl}_{2}$, 1.2 $\mathrm{MgCl}_{2}, 1.2 \mathrm{NaH}_{2} \mathrm{PO}_{4}, 25 \mathrm{NaHCO}_{3}$, and $11.5 \mathrm{D}$-glucose) at $35^{\circ} \mathrm{C}$ for blind whole-cell patch-clamp recordings. Resistances of the patch pipettes were typically $4 \mathrm{M} \Omega$. The pipette solution contained (in $\mathrm{mm}$ ) 135 K-gluconate, $0.5 \mathrm{CaCl}_{2}, 2 \mathrm{MgCl}_{2}, 5 \mathrm{KCl}, 5 \mathrm{EGTA}, 5 \mathrm{HEPES}, 5 \mathrm{D}$-glucose, 5 ATP-Mg salt, and 5 QX-314. Currents were filtered at $2 \mathrm{kHz}$ and digitized at $5 \mathrm{kHz}$ using the Axopatch 200A (Molecular Devices, Sunnyvale, CA) and analyzed by pCLAMP8.1 (Molecular Devices). Holding potential was $-70 \mathrm{mV}$ for AMPA and $-40 \mathrm{mV}$ for NMDA currents. TTX $(0.5$ $\mu \mathrm{M})$ was presented in the bath solution, except for recording evoked EPSCs (eEPSCs). Dorsal root stimulation sufficient to recruit A $\delta$ - and C-fibers was delivered with a suction electrode (Kohno et al., 2003) linked to a constant current stimulator (Digitimer, Welwyn Garden City, UK). Monosynaptic evoked EPSCs were studied in the presence of $20 \mu \mathrm{M}$ bicuculline, $2 \mu \mathrm{M}$ strychnine, and $50 \mu \mathrm{M}$ APV. Neurons were selected with either a monosynaptic A $\delta$ or C input. Ro-31-8425, H-89, phorbol12-myristate-13-acetate (PMA), PKCI 19-31, Y-27632, PD 98059, U0126, and SB 202474 were obtained from EMD Biosciences (San Diego, CA), SC-560 was a gift from Pfizer (New York, NY), and all other drugs were purchased from Sigma (St. Louis, MO).

Drugs were applied by superfusion without an alteration of the perfusion rate and temperature.

In situ hybridization and immunohistochemistry. Animals were perfused with saline followed by $4 \%$ paraformaldehyde in $0.1 \mathrm{M} \mathrm{PB}, \mathrm{pH}$ $7.4\left(4^{\circ} \mathrm{C}\right)$, and the L4-L5 spinal cord and dorsal root ganglia (DRGs) were removed, postfixed for $2 \mathrm{~h}$, and placed in PBS with $20 \%$ sucrose. An 1100 bp $B_{2}$ PCR fragment was subcloned into pCRII vector (Invitrogen, Carlsbad, CA), and digoxigenin (DIG)-UTP-labeled sense or antisense cRNA probes generated using T7/SP6 RNA polymerase (Roche, Indianapolis, IN). Sections $(10 \mu \mathrm{m})$ were acetylated $(0.25 \%$ acetic anhydride; $10 \mathrm{~min}$ ), prehybridized for $1 \mathrm{~h}$ at room temperature, incubated in hybridization buffer overnight at $55^{\circ} \mathrm{C}$, washed in SSC $(5 \times, 0.2 \times$, and $0.1 \times)$, blocked with $2 \%$ goat serum, and incubated at $4^{\circ} \mathrm{C}$ with peroxidase (1:50; Roche)-conjugated anti-DIG antibodies for overnight. Signals were enhanced by the TSA biotin system (PerkinElmer, Waltham, MA) and visualized with FITC-conjugated anti-biotin (PerkinElmer). After visualization of TSA signals, sections were incubated with primary antibody for anti-PKA (1:1000; Santa Cruz Biotechnology, Santa Cruz, CA), anti-PKC $\gamma$ (1: 5000; Santa Cruz Biotechnology), and anti-PKC $\delta$ (1:1000; Santa Cruz Biotechnology) at $4^{\circ} \mathrm{C}$ overnight. Sections were washed and then incubated with rhodamine-conjugated secondary antibody (1:100; Millipore Bioscience Research Reagents, Temecula, CA) for $2 \mathrm{~h}$ at room temperature. Images for double staining were acquired by confocal laserscanning microscopy (Axiovert 200; Zeiss, Thornwood, NY).

Western blotting. Transverse adult rat spinal cord slices $(700 \mu \mathrm{m})$ were incubated with oxygen-bubbled Krebs' solution $\left(35^{\circ} \mathrm{C}\right.$ for $\left.4 \mathrm{~h}\right)$, followed by $10 \mu \mathrm{M}$ bradykinin treatment for $3 \mathrm{~min}$ and then a 5 or $10 \mathrm{~min}$ wash. Dorsal horn tissue was homogenized in lysis buffer, separated on 4-15\% polyacrylamide gels, and transferred to nitrocellulose membranes (Immobilon-P; Millipore, Billerica, MA). The blots were incubated overnight at $4^{\circ} \mathrm{C}$ with anti-pERK1/2 antibody (1:1000; New England Biolabs,
Ipswich, MA) and probed with horseradish peroxidase-conjugated secondary antibodies using the enhanced chemiluminescence system (PerkinElmer). After stripping, the blots were reprobed with anti-ERK antibody (1:1000; New England Biolabs).

Behavior. The PKA inhibitor H-89, the PKC inhibitor Ro-31-8425, and the MEK inhibitor U0126, all at $1.5 \mu \mathrm{g}$, or vehicle (10\% DMSO) were delivered into the cerebral spinal fluid space between the L5 and L6 vertebrae via a spinal cord puncture, made by a 30 ga needle. Before puncture, the head of rats was covered by a piece of cloth. Twenty microliters of solution were injected with a microsyringe. Inside the syringe, $10 \mu \mathrm{l}$ of inhibitor $(1.5 \mu \mathrm{g})$ and $10 \mu \mathrm{l}$ of bradykinin $(2 \mu \mathrm{g})$ were separated by a small air bubble. A successful spinal puncture was confirmed by a brisk tail flick after the needle entry into subarachnoid space. Animals were put in plastic boxes and habituated to the testing environment before baseline testing. Rat paw withdrawal latency was measured using Hargreave's radiant heat test and adjusted to 9-11 s for baselines. After drug treatment, the paw withdrawal latency values were expressed as percentages of baselines.

Data analysis. Data are expressed as mean \pm SEM. Peak AMPA and NMDA currents were measured before and after each treatment and expressed as (posttreatment/pretreatment - 1) $\times 100$ (as percentages). Student's $t$ test, one-way ANOVA, and two-way ANOVA repeated measurement followed by post hoc test [SigmaStat (Systat Software, San Jose, $\mathrm{CA}$ ) and SAS (SAS Institute, Cary, NC)] were used where appropriate.

\section{Results}

\section{Activation of PKC and PKA contributes to the bradykinin- mediated potentiation of AMPA and NMDA currents in the dorsal horn}

Lamina II neurons were recorded by whole-cell patch clamp in isolated adult rat spinal cord slices with an attached dorsal root. As reported before, 3 min of preincubation with bradykinin (10 $\mu \mathrm{M})$ significantly potentiated the inward currents elicited by bath administration of either AMPA (10 $\mu \mathrm{M}$ for $30 \mathrm{~s}$, at $-70 \mathrm{mV})$ or NMDA $(50 \mu \mathrm{M}$, at $-40 \mathrm{mV})(\sim 40 \%)$, with recovery at $10 \mathrm{~min}$ (Figs. 1a,b, 2). Bradykinin also potentiated the monosynaptic AMPA receptor-mediated EPSCs (eEPSCs) evoked by A $\delta$ - and C-fiber stimulation of the dorsal root $(\sim 30 \%)$ (Figs. $1 c, d, 3)$ with onset at $2 \mathrm{~min}$, peak change at $4-5 \mathrm{~min}$, and recovery by $8-10$ min (Wang et al., 2005).

To study which signaling pathways are responsible for the bradykinin-mediated postsynaptic potentiation of AMPA and NMDA currents in the superficial dorsal horn, we used specific kinase inhibitors. Bath application independently of either the PKC inhibitor Ro-31-8425 (1 $\mu \mathrm{M})$ or the PKA inhibitor H-89 (1 $\mu \mathrm{M})$, administered $3-5$ min before the BK, blocked the potentiation of both the AMPA- and NMDA-evoked currents by bradykinin (Fig. 2).

These effects were replicated by adding into the recording pipette either PKC or PKA peptide inhibitors (5 $\mu \mathrm{M}$ PKCI 19-31 and $5 \mu \mathrm{M}$ PKAI 6-22) (Fig. 2), indicating that the potentiating effects of BK on bath-applied AMPA and NMDA are largely postsynaptic. Inhibition of Rho-kinase (ROCK) by Y-27632 (1 $\mu \mathrm{M})$ as a control had no effect (Fig. 2). H-89 alone did not change NMDA- $(105 \pm 7 \%$ of control; $n=5 ; p=0.49)$ or AMPA (101 \pm $6 \%$ of control; $n=4 ; p=0.97)$-induced currents. Ro-31-8425 did not have any effect on NMDA- $(102 \pm 5 \%$ of control; $n=3$; $p=0.72)$ or AMPA $(106 \pm 3 \%$ of control; $n=4 ; p=0.18)$ induced currents.

Inhibition of either PKA (H-89; $1 \mu \mathrm{M})$ or PKC (Ro-31-8425; 1 $\mu \mathrm{M})$ also blocked the potentiation produced by bradykinin of both $\mathrm{A} \delta$ - and C-fiber eEPSCs (Fig. 3). H-89 alone did not change A $\delta(104 \pm 4 \%$ of control; $n=3 ; p=0.48)$ - and C $(103 \pm 3 \%$ of control; $n=3 ; p=0.34$ )-fiber-evoked EPSCs. Ro-31-8425 alone did not have any effect on $\mathrm{A} \delta(100 \pm 10 \%$ of control; $n=3 ; p=$ 
a

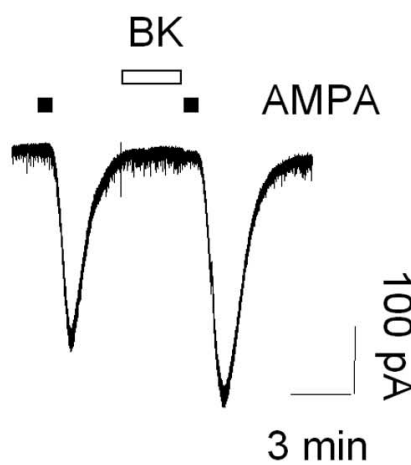

C

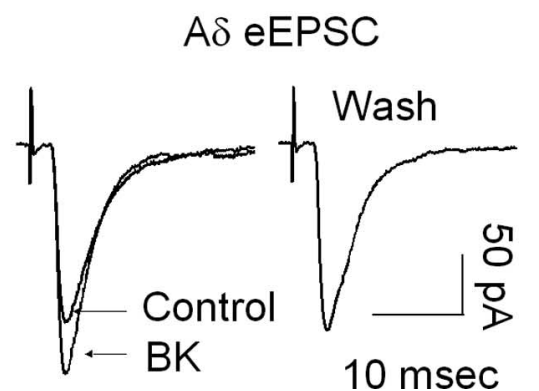

b

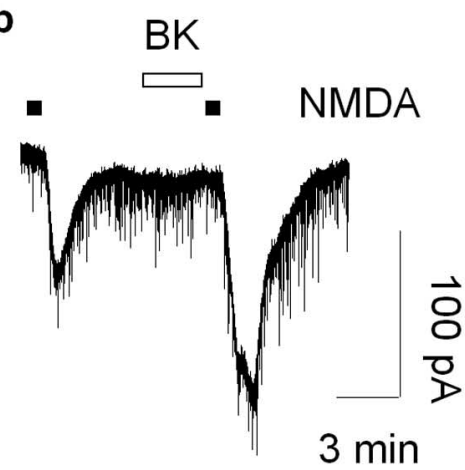

d

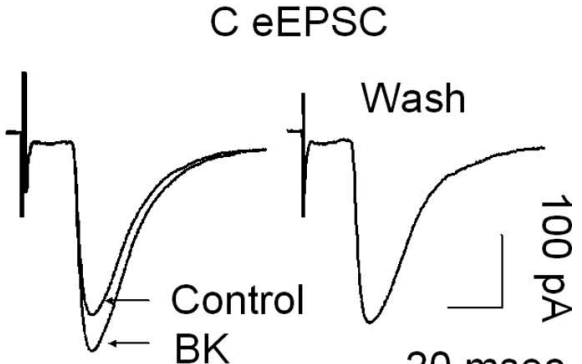

$20 \mathrm{msec}$

Figure 1. Bradykinin enhances glutamatergic responsiveness in superficial dorsal horn neurons. $\boldsymbol{a}, \boldsymbol{b}$, Representative traces from whole-cell patch-clamped lamina II neurons indicate that BK (10 $\mu \mathrm{m}, 3 \mathrm{~min}$; open box) potentiates AMPA (10 $\mu \mathrm{m} ; \boldsymbol{a})$ and NMDA $(50 \mu \mathrm{m} ; \boldsymbol{b})$ currents. $\boldsymbol{c}, \boldsymbol{d}$, Representative traces of $A \delta(\boldsymbol{c})$ - and C (d)-fiber-evoked EPSCs (average of 5 sweeps) before, during, and after application of BK (10 $\mu \mathrm{m})$.

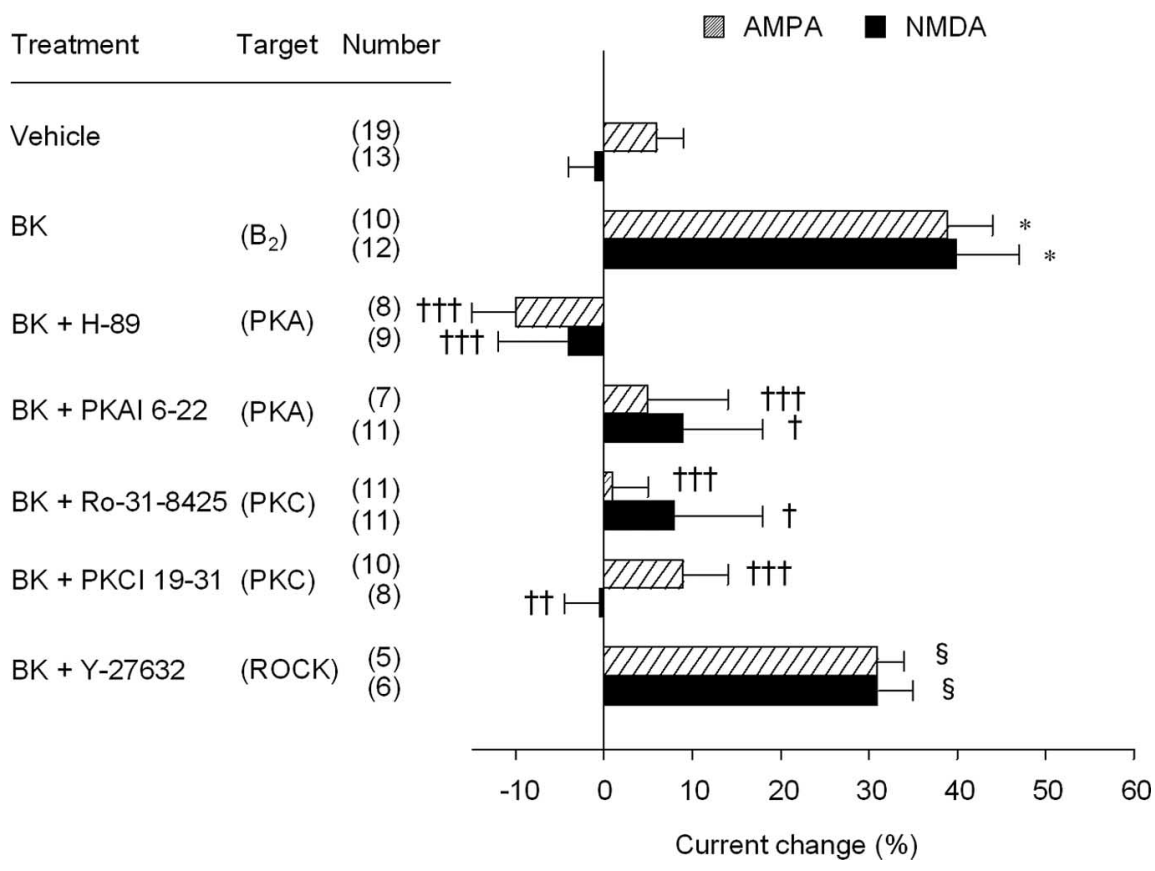

Figure 2. Blockade by kinase inhibitors of the bradykinin-mediated potentiation of AMPA and NMDA currents. BK potentiates both AMPA (hatched bars) and NMDA (filled bars) currents. This potentiation is blocked by the PKA inhibitors H-89 (1 $\mu$ m; bath applied) and PKAI 6-22 (5 $\mu \mathrm{m}$; in pipette) and the PKC inhibitors Ro-31-8425 (1 $\mu \mathrm{m}$; bath applied) and PKCI $19-31$ (5 $\mu \mathrm{m}$; in pipette). A Rho-kinase inhibitor, Y-27632 (1 $\mu$ m; bath applied), had no effect. Data are shown as means $\pm \mathrm{SEM} .{ }^{\dagger} p<0.05,{ }^{\dagger \dagger} p<$ $0.01,{ }^{\dagger+} p<0.001,{ }^{\S} p>0.05$ compared with bradykinin; ${ }^{*} p<0.001$ compared with vehicle.

0.98)- and C (101 $\pm 8 \%$ of control; $n=3$; $p=0.94)$-fiber-evoked EPSCs. We conclude that activation of both PKA and PKC is required for the augmentation of AMPA or NMDA receptor responsiveness in superficial dorsal horn neurons and that this might occur in parallel or in series.

Do PKA and PKC activators mimic the effects of bradykinin?

Administration of either the PKA activator 8-bromo-cAMP (0.25 mM) or the PKC activator PMA $(1 \mu \mathrm{M})$ separately failed to alter NMDA or AMPA currents (Fig. $4 a, b$ ). However, coadministration of 8-bromocAMP with PMA potentiated both NMDA and AMPA currents by $\sim 80 \%$ (Fig. $4 a, b$ ). We interpret this as indicating that a coactivation of the kinases by $\mathrm{BK}$ is required to augment glutamate responsiveness.

Using in situ hybridization for $\mathrm{B}_{2}$ mRNA, we previously reported that $\mathrm{B}_{2}$ receptors are extensively expressed in rat dorsal horn neurons (Wang et al., 2005). We now find that the $B_{2}$ mRNA is colocalized with both PKA and the PKC $\delta$ isoform, but not with PKC $\gamma$ (Fig. 5). PKC $\gamma$-positive neurons are located in lamina IIi, and $\mathrm{B}_{2}$, PKA, and PKC $\delta$ are found in lamina II, where the electrophysiological recordings were made. The coexpression of $\mathrm{B}_{2}$, PKA, and $\mathrm{PKC} \delta$ in dorsal horn neurons provides a basis for the augmentation of glutamatergic responses by these kinases downstream of $\mathrm{B}_{2}$ activation.

\section{Does the bradykinin-mediated activation of PKA occur via prostanoid production?}

BK's actions in several non-neuronal systems are cyclooxygenase dependent (Szerafin et al., 2006; Brechter and Lerner, 2007), and prostanoids, via their EP receptors, increase adenylate cyclase activity and thereby PKA (Regan, 2003). EP2 receptors are widely expressed on dorsal horn neurons (Kawamura et al., 1997). We found that a nonselective Cox-1 and Cox-2 inhibitor, ibuprofen (50 $\mu \mathrm{M}$; data not shown), and the Cox-1 inhibitor SC-560 (1 $\mu \mathrm{M})$ eliminated the $\mathrm{B}_{2}$-mediated potentiation of AMPA and NMDA currents (Fig. 6a), whereas a Cox-2-selective inhibitor, NS$398(10 \mu \mathrm{M})$, was without effect (Fig. 6a).

$\mathrm{PGE}_{2}(10 \mu \mathrm{M})$ administered alone had no effect, but when coadministered with PMA augmented NMDA and AMPA currents (Figs. $4 a, 6 b$ ). This finding, together with the action of COX-1 inhibitors, indicates that $\mathrm{PGE}_{2}$ is likely to contribute, by activating PKA, to the augmenting effect of bradykinin on synaptic transmission in superficial dorsal horn neurons. 


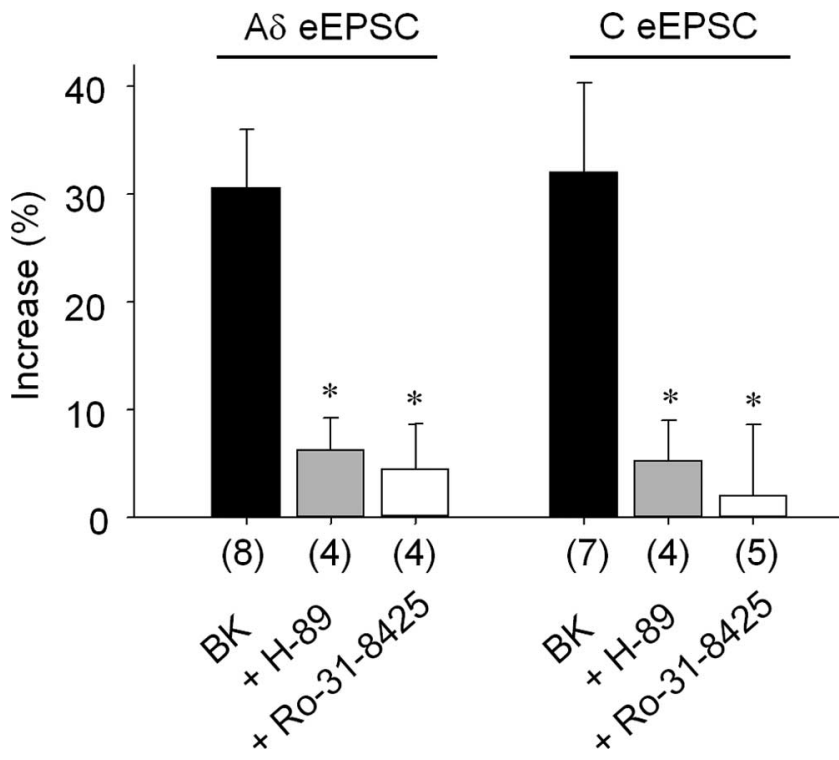

Figure 3. Blockade by kinase inhibitors of the bradykinin-mediated potentiation of evoked EPSCs. Pretreatment with the PKA inhibitor H-89 (1 $\mu$; gray box) or the PKC inhibitor Ro-318425 ( $1 \mu \mathrm{m}$; open box) blocks the BK-induced ( $10 \mu \mathrm{m}$; black box) potentiation of $A \delta$ and $C$ eEPSCs. Data are shown as means \pm SEM. ${ }^{*} p<0.05$. The numbers of cells are indicated in parentheses.

ERK activation is downstream of the coactivation of PKC and PKA by $B_{2}$

We interpret the requirement for coactivation of PKA and PKC activators as showing that these kinases may converge on a common effector. One downstream candidate is the MAPK ERK (Naraba et al., 1998; Mukhin et al., 2003). ERK integrates PKA and $\mathrm{PKC}$ signaling in superficial dorsal horn neurons to produce neuronal hyperexcitability (Hu and Gereau, 2003; Hu et al., 2003; Kawasaki et al., 2004), and activated ERK plays a role in central sensitization (Ji et al., 1999; Kawasaki et al., 2004).

Exposure of isolated spinal cord slices to bradykinin $(10 \mu \mathrm{M})$ for $3 \mathrm{~min}$ induced an increase in phospho-ERK (pERK)immunoreactive neurons in the dorsal horn, including those in lamina II (Fig. 7a), with a 1.5-fold and twofold increase determined by Western blot (Fig. 7b). The potentiation of AMPA and NMDA currents by bradykinin was prevented by pretreatment with the MAPK kinase (MEK) inhibitor PD 98059 (50 $\mu \mathrm{M})$ (Fig. $7 c$ ), which blocks the phosphorylation (activation) of ERK. An inactive isoform of the MEK inhibitor SB 202474 (50 $\mu \mathrm{M}$ ), widely used as a negative control, was without effect (Fig. 7c). The potentiation of AMPA and NMDA currents produced by the coadministration of 8-Br-cAMP and PMA was also inhibited by pretreatment of PD 98059 (Fig. 7c). ERK activation is necessary, therefore, for the effects of bradykinin and of PKA/PKC coactivation on NMDA and AMPA receptors in superficial dorsal horn neurons.

Intrathecal administration of bradykinin $(2 \mu \mathrm{g})$ produced thermal hyperalgesia when measured by a reduced latency of response to a standard radiant heat stimulus $(n=11)$, with an onset of $30 \mathrm{~min}$, a peak decrease in the thermal response latency at $90 \mathrm{~min}$, and slow recovery by $4 \mathrm{~h}$ (Fig. 8). The animals need some time to calm down after the drug injection via spinal puncture, which makes it difficult to measure behavior at early time points $(<15 \mathrm{~min}$ ). Pretreatment with intrathecal administration of the PKA inhibitor H-89, the PKC inhibitor Ro-31-8425, or the MEK inhibitor U0126 (all $1.5 \mu \mathrm{g}$ ), but not vehicle, significantly re- a

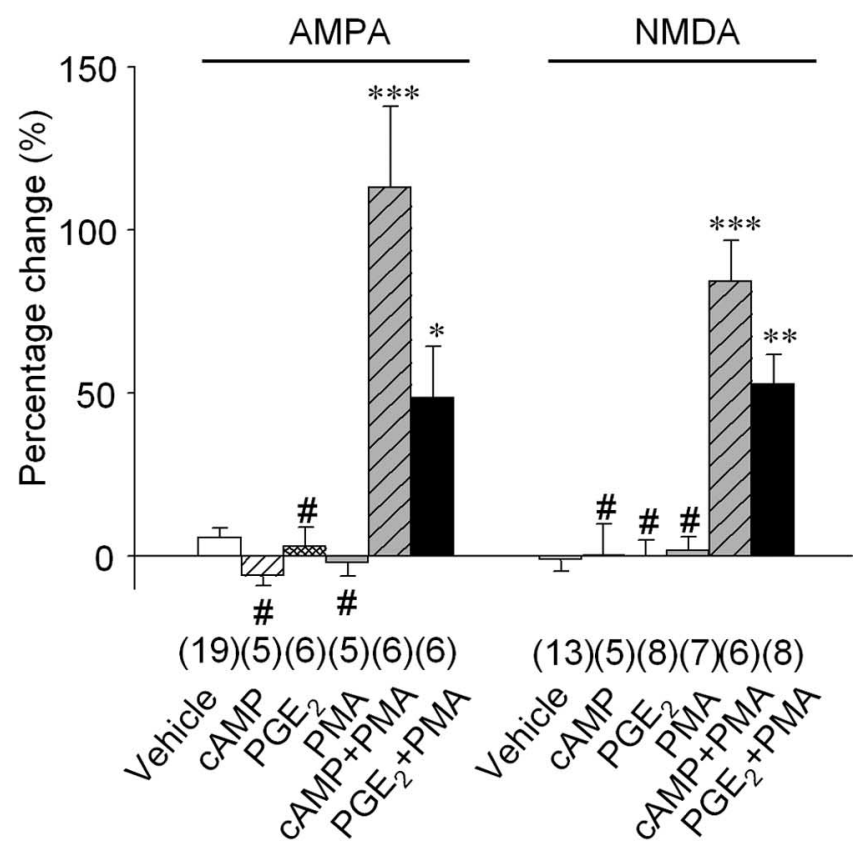

b

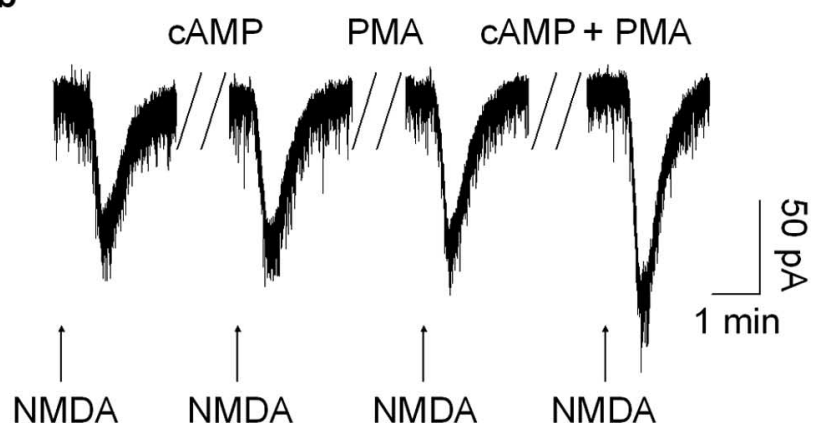

Figure 4. Coactivation of PKA and PKC potentiates AMPA and NMDA currents. $\boldsymbol{a}$, Administration of 8-bromo-CAMP (CAMP; $0.25 \mathrm{mM}), \mathrm{PGE}_{2}(10 \mu \mathrm{M})$, and PMA (1 $\left.\mu \mathrm{M}\right)$ separately fail to alter AMPA or NMDA currents. In contrast, coadministration of either $\mathrm{CAMP}$ or $\mathrm{PGE}_{2}$ with PMA potentiates the currents. Data are shown as means \pm SEM. ${ }^{*} p<0.05 ;{ }^{* *} p<0.01 ;{ }^{* * *} p<$ $0.001 ;{ }^{\#} p>0.05 . \boldsymbol{b}$, Representative traces showing that although administration of CAMP or PMA alone does not potentiate NMDA currents in dorsal horn neurons, their coadministration does.

duced the intrathecal bradykinin-induced thermal hyperalgesia in all cases (Fig. 8) $(n=8 ; p<0.05)$, indicating that this behavioral measure in vivo, like the glutamatergic potentiation in vitro, is dependent on downstream PKA, PKC, and ERK activation. However, one caveat about interpreting this data is that it is not possible in such in vivo experiments to differentiate between an effect of the inhibitors on primary afferent presynaptic terminals and one on postsynaptic neurons. Another caveat is the delayed onset of bradykinin-induced hyperalgesia.

\section{Discussion}

We previously reported that $\mathrm{B}_{2}$ receptor activation by bradykinin in adult rat spinal cord slices augmented primary afferent evoked glutamatergic synaptic currents, the frequency and amplitude of spontaneous AMPA-mediated mEPSCs, and the currents evoked directly by bath application of AMPA and NMDA in lamina II spinal cord neurons (Wang et al., 2005). These electrophysiological data suggested both a presynaptic action of bradykinin on the 

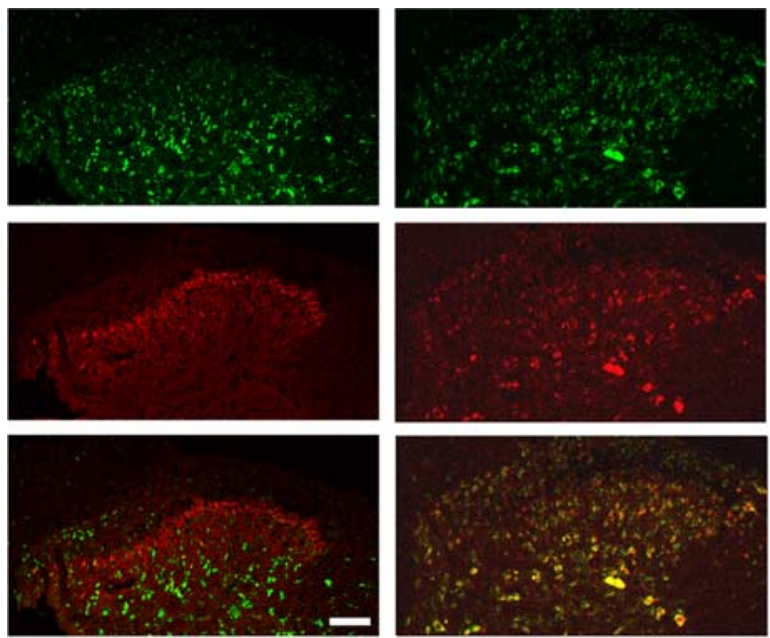

$\mathrm{PKCy/B2}$

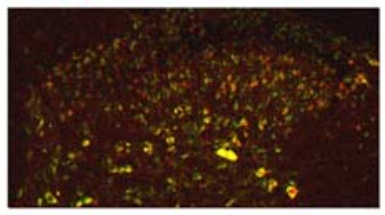

$\mathrm{PKC} \delta / \mathrm{B} 2$
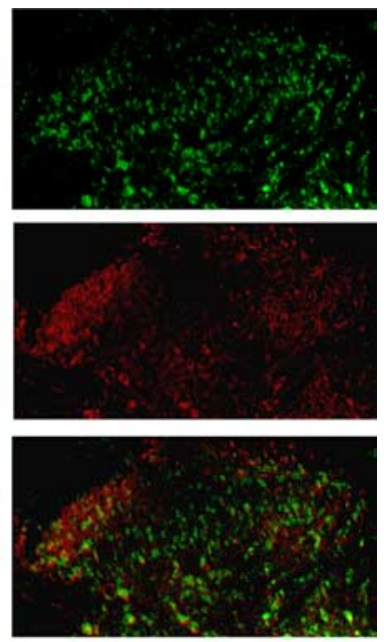

PKA/B2

Figure 5. Colocalization of $B_{2}$ receptor mRNA with PKA and PKC in dorsal horn neurons. Fluorescent in situ hybridization for $B_{2}$ receptor mRNA in dorsal horn neurons and expression of PKA, PKC $\gamma$, and PKC $\delta$. $B_{2}$ receptors colocalize with PKA and PKC $\delta$. PKC $\gamma$ staining identifies neurons in lamina Ili. Scale bar, $100 \mu \mathrm{m}$.

central axonal terminals of DRG neurons and a postsynaptic action on dorsal horn neurons, findings compatible with the localization of $B_{2}$ receptor $m R N A$ in small-caliber DRGs and in $\mathrm{NR}_{1}$ expressing dorsal horn neurons (Wang et al., 2005).

We now show that the augmentation of NMDA and AMPA currents in dorsal horn neurons appears to require coactivation of both PKA and PKC. This was indicated first by the finding that either PKA or PKC inhibitors could independently block the potentiating action of bradykinin, and second by the finding that both PKA and PKC activators need to be present to increase AMPA or NMDA currents. We hypothesize based on these data that the $\mathrm{B}_{2}$ receptor in dorsal horn neurons directly activates $\mathrm{PKC}$ through DAG and intracellular $\mathrm{Ca}^{2+}$ release, and indirectly activates PKA through the production of $\mathrm{PGE}_{2}$, with activation of adenyl cyclase secondary to EP receptor activation (Fig. 9). A similar convergent regulation by PKA and PKC occurs for voltage-gated sodium channels (Li et al., 1993) and the glycine receptor ( $\mathrm{Gu}$ and Huang, 1998).

We further show that downstream of the PKA and PKC coactivation by bradykinin is an activation of ERK. Bradykinin, then, like primary afferent nociceptor inputs, induces pERK in dorsal horn neurons (Ji et al., 1999; Xin et al., 2006; Polgár et al., 2007). Blocking ERK activation by inhibiting MEK diminishes both the $\mathrm{B}_{2}$-mediated potentiation of excitatory synaptic transmission and the enhancement produced by coadministration of PKA and PKC activators. The attenuation by MEK, PKC, and PKA inhibitors of intrathecal bradykinin-induced thermal hyperalgesia indicates, moreover, that these findings may relate to pain behavior. These findings are consistent with our previous studies showing that MEK inhibition reduces the second phase of the formalin test (Ji et al., 1999) and secondary mechanical allodynia in the intraplantar capsaicin test (Kawasaki et al., 2004), which are both models of activity-dependent central sensitization. Mice with a null mutation of the $\mathrm{B}_{2} \mathrm{BK}$ receptor also have reduced secondary mechanical allodynia in the capsaicin model (Wang et al., 2005). Interestingly, bradykinin via $B_{2}$ activates ERK in several other cells (Liu et al., 2006; Hsieh et al., 2007; Yu et al., 2007). PKC activates Raf and PKA Rap1, and thereby B-Raf (Gutkind, 2000). Both Raf and B-Raf can activate MEK, which in turn acti- vates ERK (Gutkind, 2000). Bradykinin activation of PKC leads to an activation of ERK in astrocytes (Hsieh et al., 2007).

ERK activation in superficial dorsal horn neurons after C-fiber stimulation relies on both PKA and PKC (Kawasaki et al., 2004) and modulates A-type $\mathrm{K}^{+}$currents in a manner that involves both PKA and PKC signaling ( $\mathrm{Hu}$ and Gereau, 2003; $\mathrm{Hu}$ et al., 2003, 2006; Xin et al., 2006). ERK activation by bradykinin results in rapid changes in NMDA and AMPA receptors that appear within minutes, but whether these are mediated by posttranslational changes in receptor kinetics or receptor insertion into the membrane, and if there are any intervening signaling kinases between ERK and the receptors, now need to be established. It is somewhat surprising that the two quite distinct receptors show a very similar pattern of potentiation by BK. ERK activation in dorsal horn neurons after peripheral inflammation also leads to alterations in the transcription of prodynorphin and NK1 (Ji et al., 2002), but this only occurs after many hours. There are therefore both transcription-independent and transcription-dependent actions of this MAPK in the dorsal horn. The timing and extent of the BK-induced changes we observed in glutamate responsiveness were very similar for bathapplied AMPA and NMDA and the A $\delta$ - or C-fiber-evoked synaptic currents, even though bath application will lead to activation of synaptic and extrasynaptic receptors and could produce indirect effects by mediators released from the slices in response to AMPA and NMDA application.

The activation of PKA in response to $\mathrm{B}_{2}$ depends on prostanoid production by Cox-1. Cox-1 is constitutively expressed in the spinal cord in noninflamed animals and produces $\mathrm{PGE}_{2}$ in response to nociceptor inputs (Dirig et al., 1997; Tegeder et al., 2001). Intrathecally delivered Cox-1-selective inhibitors attenuate the second phase of the formalin test (Dirig et al., 1997; Tegeder et al., 2001), a model of central sensitization. Low levels of Cox-2 are present constitutively in the spinal cord, mainly in endothelial cells, but this enzyme is substantially induced in dorsal horn neurons some hours after peripheral inflammation, contributing to late inflammatory pain hypersensitivity (Samad et al., 2001). It is possible, then, that bradykinin may begin to act via Cox-2 in the dorsal horn after peripheral inflammation. Interestingly, the sensitizing action of bradykinin on nociceptor terminals in the skin also acts via cyclooxygenase products (Petho et al., 2001; Inoue et al., 2006; Levy and Fleisher-Berkovich, 2007; Mayer et al., 2007). Bradykinin appears then to be a driver of prostanoid-produced pain both in the periphery and in the spinal cord.

PKA or PKC can increase glutamate receptor function through direct phosphorylation (Yu et al., 1997; Esteban et al., 2003), and it is therefore curious that PKA or PKC alone were not able to modify AMPA or NMDA currents in the present study. This apparent discrepancy could be attributable to unique characteristics of lamina II neurons. However, our data suggest that ERK activation is downstream of PKA/PKC activation, and one possible scenario is that whereas PKA and PKC activate ERK individually, and therefore in some circumstances modulate NMDA and AMPA receptors, such individual effects in lamina II 
a

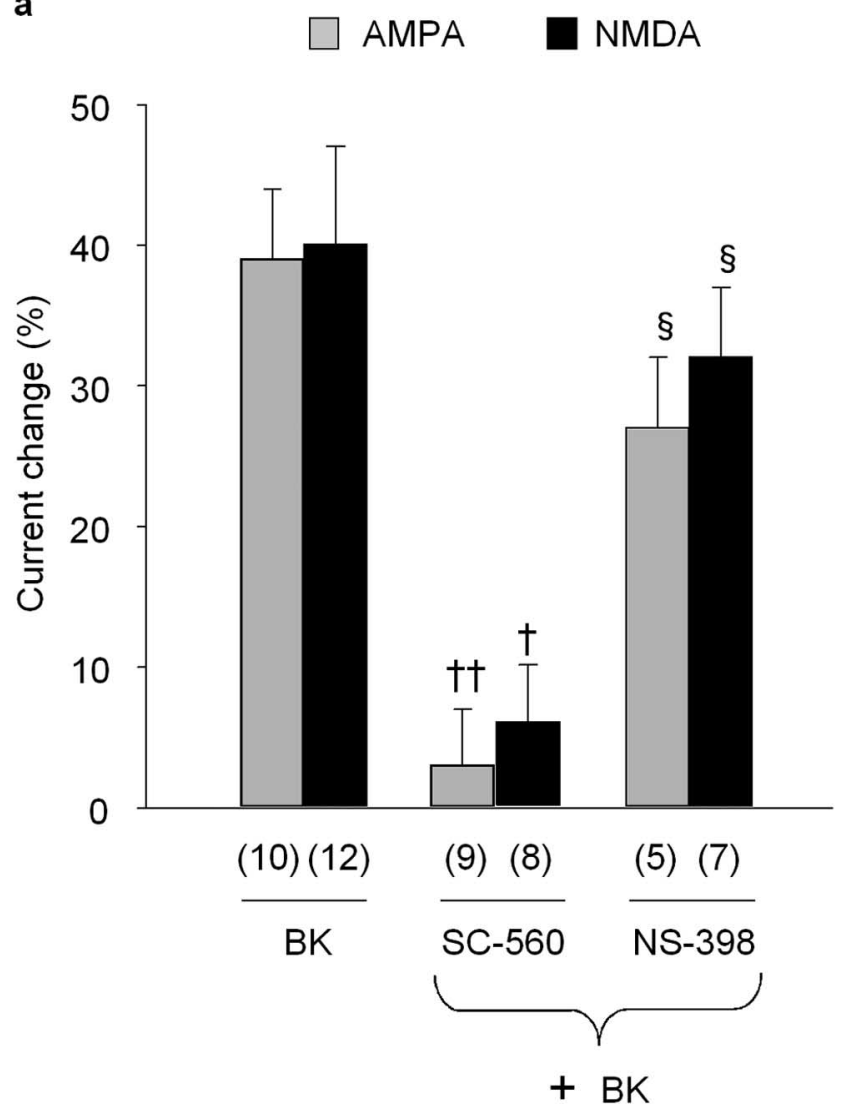

b
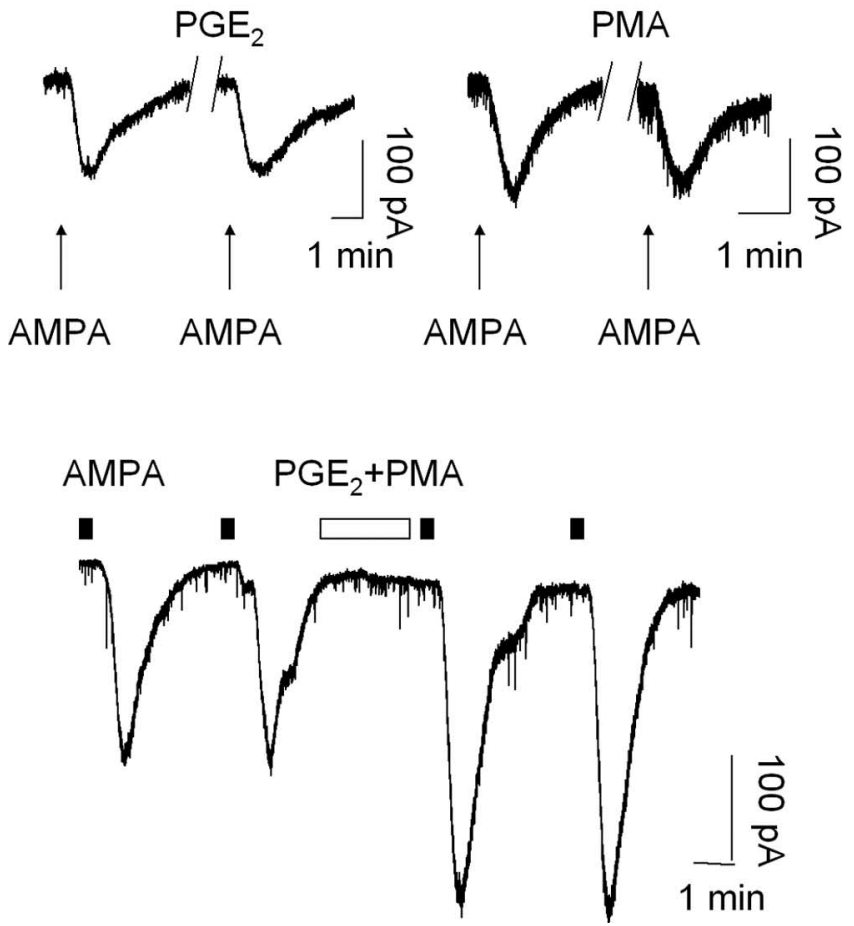

Figure 6. Bradykinin-mediated potentiation of AMPA and NMDA currents requires Cox-1.a, BK potentiation of AMPA and NMDA currents is blocked by a Cox-1-selective inhibitor, SC-560 (1 $\mu \mathrm{M})$, whereas a Cox-2-selective inhibitor, NS-398 $(10 \mu \mathrm{M})$, has no effect. Data are shown as means \pm SEM. ${ }^{\dagger} p<0.05 ;{ }^{\dagger+} p<0.001 ;{ }^{\S} p>0.05 . b$, Separate administration of either $\mathrm{PGE}_{2}$ or PMA does not potentiate AMPA currents in dorsal horn neurons, but coadministration of $\mathrm{PGE}_{2}$ with PMA does. a
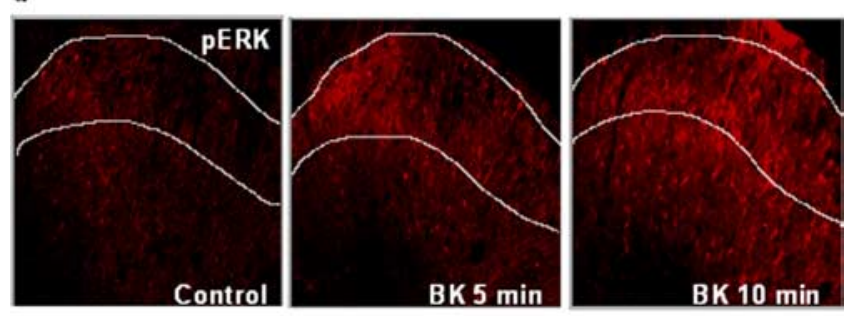

b

Control $5 \mathrm{~min} 10 \mathrm{~min}$

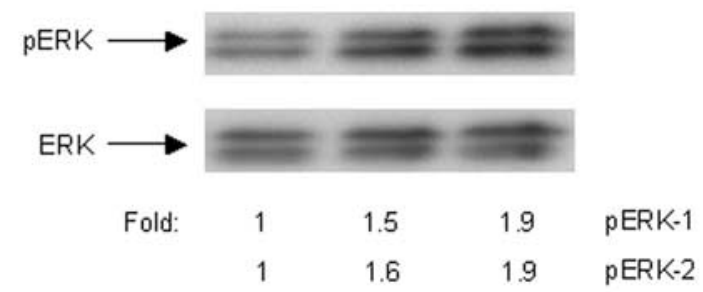

c

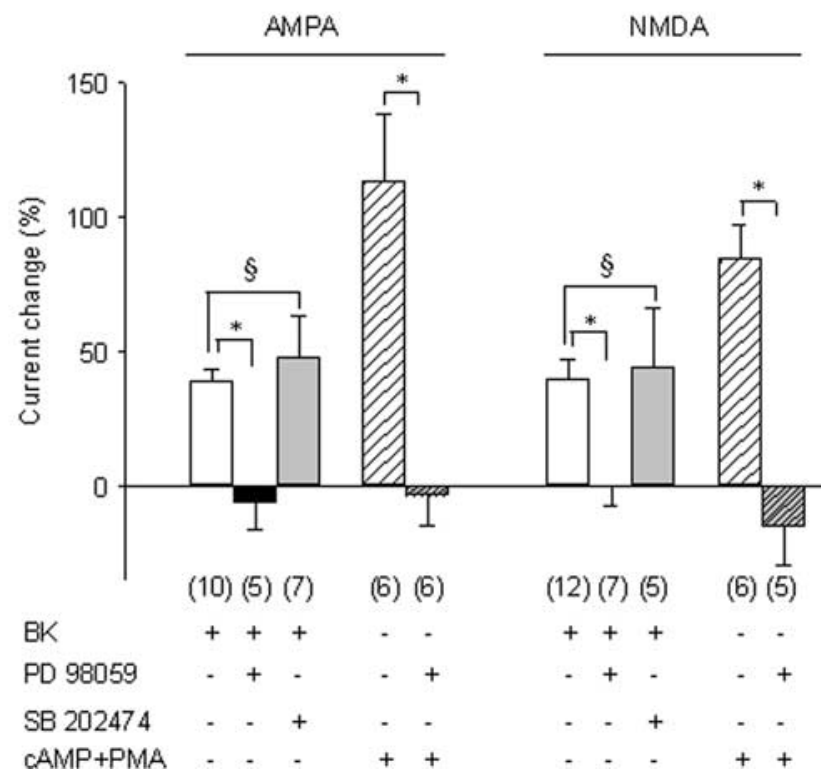

Figure 7. BK activates ERK in the dorsal horn. $\boldsymbol{a}, \boldsymbol{b}$, Basal levels of pERK in isolated spinal cord slices are low (left), but bath application of BK (10 $\mu \mathrm{m})$ increases the levels in the dorsal horn, as observed by immunostaining (the outline of the superficial dorsal horn, laminas I-II, is indicated; $\boldsymbol{a}$ ) and by Western blots (fold change indicated; $\boldsymbol{b}$ ). $\boldsymbol{c}$, The BK-mediated potentiation of AMPA and NMDA currents is blocked by pretreatment with the MEK inhibitor PD 98059 (50 $\mu \mathrm{m}$ ) but not by an inactive isoform, SB $202474(50 \mu \mathrm{M})$. The augmentation of AMPA and NMDA currents produced by coadministration of 8-Br-cAMP and PMA is inhibited by PD 98059 (50 $\mu \mathrm{m})$. The numbers of cells are indicated in parentheses. ${ }^{\S} p>0.05$; ${ }^{*} p<0.05$.

neurons do not always reach the threshold required to produce detectable changes.

Activity-dependent central sensitization is induced by activity in C-fibers and manifests by a short-latency amplification of nociceptive responses (hyperalgesia), a reduction in threshold (allodynia), and the spatial expansion of sensitivity (increased receptive fields and secondary hyperalgesia). Globally, these features are the manifestation of increases in synaptic strength in the dorsal horn as a result of homosynaptic and heterosynaptic facilitations, reductions in inhibition, and elevations in membrane excitability. Multiple parallel signals acting presynaptically and postsynaptically can separately and together contribute to 

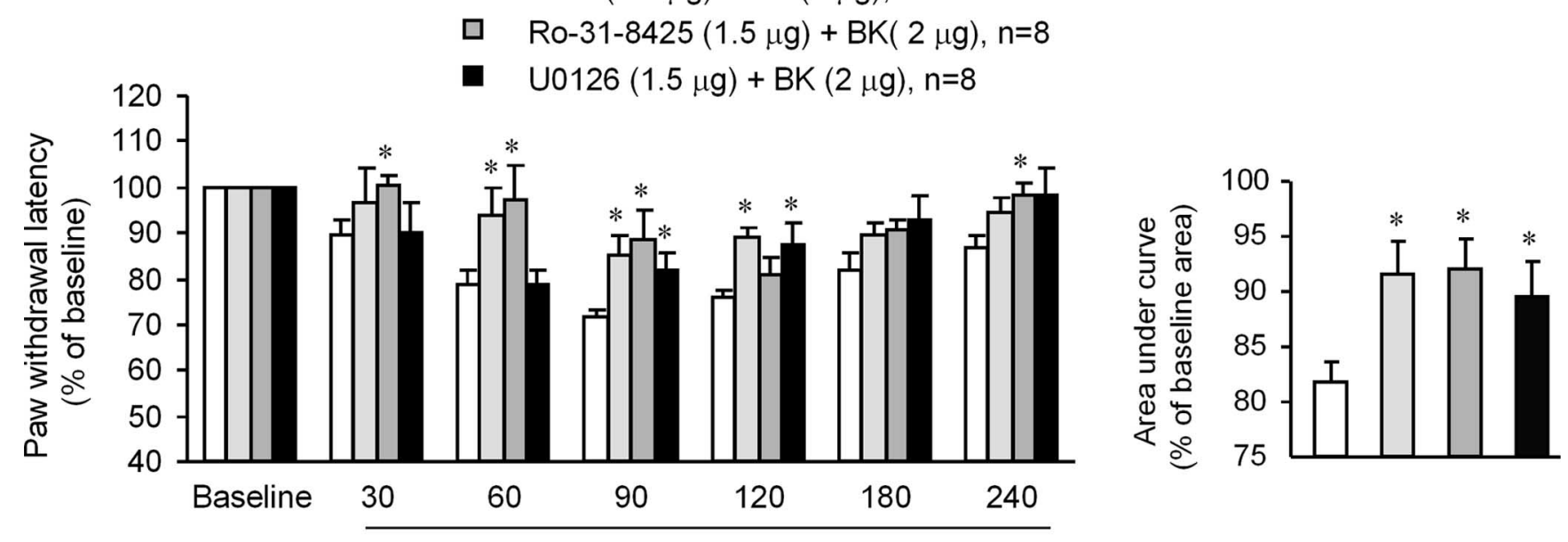

Time (min) after drug injection

Figure 8. Attenuation of BK-induced thermal hyperalgesia by MEK, PKA, and PKC inhibitors. $\boldsymbol{a}$, Intrathecal administration of BK (2 $\mu \mathrm{g}$; white box) decreases the withdrawal latency in the Hargreave's noxious radiant heat test, and this is attenuated by intrathecal treatment with the PKA inhibitor H-89, the PKC inhibitor Ro-31-8425, and the MEK inhibitor U0126 (1.5 $\mu \mathrm{g})$. DMSO (10\%) was used as a vehicle for all inhibitors. The data were expressed as percentages of baseline paw withdrawal latency. ${ }^{*} p<0.05$, ANOVA, compared with BK control $(n=8-11)$. $\boldsymbol{b}, 0$ verall effects of the inhibitors at 30-240 min after drug injections, as demonstrated as the area under the curve. The baseline area was regarded as 100\%. ${ }^{*} p<0.05$, ANOVA, compared with BK control ( $\left.n=8-11\right)$.

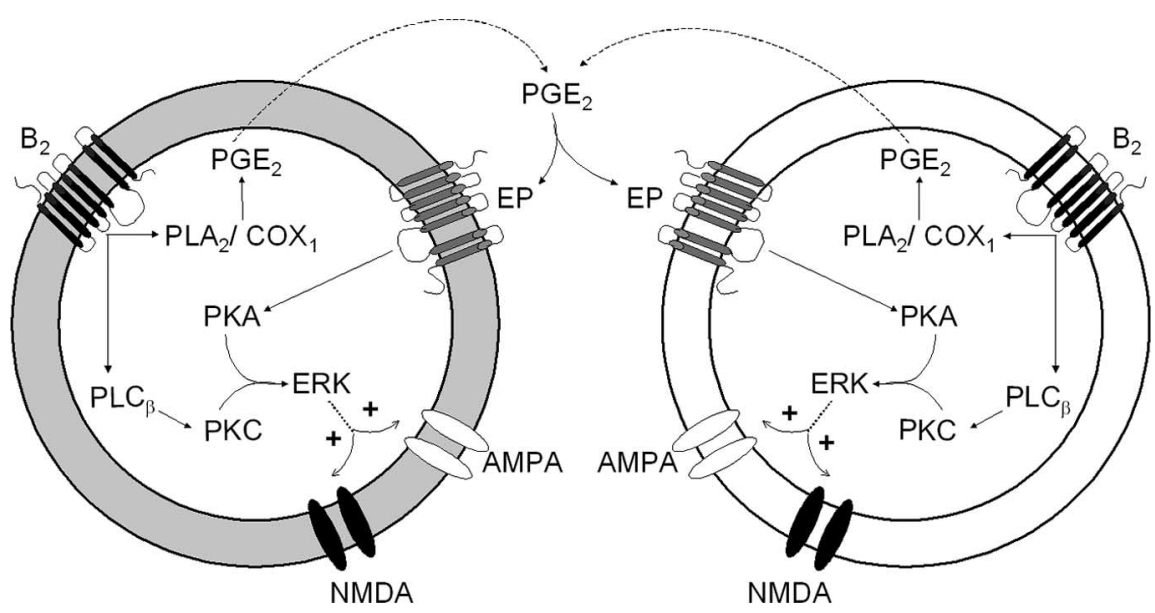

Figure 9. Ascheme of the possible signaling pathways for the BK-mediated potentiation of AMPA and NMDA currents in dorsal horn neurons.

central sensitization, including glutamate through ionotropic and metabotropic receptors, substance $\mathrm{P}$ via NK1, BDNF via TrkB, NO via multiple effectors, $\mathrm{PGE}_{2}$ via $\mathrm{EP} 4$ presynaptically, and EP2 postsynaptically (Woolf and Salter, 2000; Ji et al., 2003). We argue, based on our earlier data (Wang et al., 2005) and that presented in this study, that BK contributes to the induction of central sensitization. This is based on the following evidence. BK levels in the spinal cord increase after intraplantar capsaicin, $B_{2}$ knock-out or inhibition reduces behavioral models of central sensitization (intraplantar formalin and capsaicin), and BK facilitates glutamatergic transmission (Wang et al., 2005). We now show in vitro that a component of BK's action in increasing glutamate responsiveness involves activation of multiple kinases and that inhibition of these in vivo reduces pain hypersensitivity produced by BK. However, these kinases are unlikely to be exclusively activated by $\mathrm{BK}$, and almost certainly other aspects of central sensitization may act independently either of these kinases or of an increase in postsynaptic glutamate sensitivity.

\section{Conclusion}

$\mathrm{B}_{2}$ activation by bradykinin produces multiple presynaptic and postsynaptic effects on glutamate transmission in dorsal horn neurons and contributes to activitydependent changes in transmission in the spinal cord and central sensitization. The action of bradykinin upstream of multiple signaling pathways that modify neuronal excitability in the PNS to produce peripheral sensitization as well as in the CNS to generate central sensitization indicates that preventing its production using kallikrein inhibitors or action with $\mathrm{B}_{2}$ receptor antagonists may provide useful means for controlling acute pain hypersensitivity.

\section{References}

Brechter AB, Lerner UH (2007) Bradykinin potentiates cytokine-induced prostaglandin biosynthesis in osteoblasts by enhanced expression of cyclooxygenase 2, resulting in increased RANKL expression. Arthritis Rheum 56:910-923.

Carroll RC, Zukin RS (2002) NMDA-receptor trafficking and targeting: implications for synaptic transmission and plasticity. Trends Neurosci 25:571-577.

Chapman V, Dickenson AH (1992) The spinal and peripheral roles of bradykinin and prostaglandins in nociceptive processing in the rat. Eur J Pharmacol 219:427-433.

Cook AJ, Woolf CJ, Wall PD, McMahon SB (1987) Dynamic receptive field plasticity in rat spinal cord dorsal horn following $\mathrm{C}$ primary afferent input. Nature 325:151-153.

Couture R, Harrisson M, Vianna RM, Cloutier F (2001) Kinin receptors in pain and inflammation. Eur J Pharmacol 429:161-176.

Dirig DM, Konin GP, Isakson PC, Yaksh TL (1997) Effect of spinal cyclooxygenase inhibitors in rat using the formalin test and in vitro prostaglandin E2 release. Eur J Pharmacol 331:155-160.

Esteban JA, Shi SH, Wilson C, Nuriya M, Huganir RL, Malinow R (2003) PKA phosphorylation of AMPA receptor subunits controls synaptic trafficking underlying plasticity. Nat Neurosci 6:136-143.

Ferreira J, Campos MM, Araujo R, Bader M, Pesquero JB, Calixto JB (2002) 
The use of kinin $\mathrm{B}(1)$ and $\mathrm{B}(2)$ receptor knockout mice and selective antagonists to characterize the nociceptive responses caused by kinins at the spinal level. Neuropharmacology 43:1188-1197.

Gu Y, Huang LY (1998) Cross-modulation of glycine-activated Cl- channels by protein kinase $\mathrm{C}$ and cAMP-dependent protein kinase in the rat. J Physiol (Lond) 506:331-339.

Gutkind JS (2000) Regulation of mitogen-activated protein kinase signaling networks by G protein-coupled receptors. Sci STKE 2000:RE1.

Hartmann B, Ahmadi S, Heppenstall PA, Lewin GR, Schott C, Borchardt T, Seeburg PH, Zeilhofer HU, Sprengel R, Kuner R (2004) The AMPA receptor subunits GluR-A and GluR-B reciprocally modulate spinal synaptic plasticity and inflammatory pain. Neuron 44:637-650.

Hsieh HL, Wang HH, Wu CY, Jou MJ, Yen MH, Parker P, Yang CM (2007) BK-induced COX-2 expression via PKC-delta-dependent activation of p42/p44 MAPK and NF-kappaB in astrocytes. Cell Signal 19:330-340.

$\mathrm{Hu} \mathrm{HJ}$, Gereau IV RW (2003) ERK integrates PKA and PKC signaling in superficial dorsal horn neurons. II. Modulation of neuronal excitability. J Neurophysiol 90:1680-1688.

Hu HJ, Glauner KS, Gereau IV RW (2003) ERK integrates PKA and PKC signaling in superficial dorsal horn neurons. I. Modulation of A-type K+ currents. J Neurophysiol 90:1671-1679.

Hu HJ, Carrasquillo Y, Karim F, Jung WE, Nerbonne JM, Schwarz TL, Gereau IV RW (2006) The kv4.2 potassium channel subunit is required for pain plasticity. Neuron 50:89-100.

Inoue A, Iwasa M, Nishikura Y, Ogawa S, Nakasuka A, Nakata Y (2006) The long-term exposure of rat cultured dorsal root ganglion cells to bradykinin induced the release of prostaglandin E2 by the activation of cyclooxygenase-2. Neurosci Lett 401:242-247.

Ji RR, Baba H, Brenner GJ, Woolf CJ (1999) Nociceptive-specific activation of ERK in spinal neurons contributes to pain hypersensitivity. Nat Neurosci 2:1114-1119.

Ji RR, Befort K, Brenner GJ, Woolf CJ (2002) ERK MAP kinase activation in superficial spinal cord neurons induces prodynorphin and NK-1 upregulation and contributes to persistent inflammatory pain hypersensitivity. J Neurosci 22:478-485.

Ji RR, Kohno T, Moore KA, Woolf CJ (2003) Central sensitization and LTP: do pain and memory share similar mechanisms? Trends Neurosci 26:696-705.

Kawamura T, Yamauchi T, Koyama M, Maruyama T, Akira T, Nakamura N (1997) Expression of prostaglandin EP2 receptor mRNA in the rat spinal cord. Life Sci 61:2111-2116.

Kawasaki Y, Kohno T, Zhuang ZY, Brenner GJ, Wang H, Van Der MC, Befort K, Woolf CJ, Ji RR (2004) Ionotropic and metabotropic receptors, protein kinase A, protein kinase $\mathrm{C}$, and Src contribute to C-fiber-induced ERK activation and cAMP response element-binding protein phosphorylation in dorsal horn neurons, leading to central sensitization. J Neurosci 24:8310-8321.

Kohno T, Moore KA, Baba H, Woolf CJ (2003) Peripheral nerve injury alters excitatory synaptic transmission in lamina II of the rat dorsal horn. J Physiol (Lond) 548:131-138.

Levy E, Fleisher-Berkovich S (2007) Regulation of glial cyclooxygenase by bradykinin. Peptides 28:845-850.

Li M, West JW, Numann R, Murphy BJ, Scheuer T, Catterall WA (1993) Convergent regulation of sodium channels by protein kinase $\mathrm{C}$ and cAMP-dependent protein kinase. Science 261:1439-1442.

Liu B, Yu J, Taylor L, Zhou X, Polgar P (2006) Microarray and phosphokinase screenings leading to studies on ERK and JNK regulation of connective tissue growth factor expression by angiotensin II 1a and bradykinin B2 receptors in Rat1 fibroblasts. J Cell Biochem 97:1104-1120.

Mayer S, Izydorczyk I, Reeh PW, Grubb BD (2007) Bradykinin-induced nociceptor sensitisation to heat depends on cox- 1 and cox- 2 in isolated rat skin. Pain 130:14-24.
Mukhin YV, Garnovsky EA, Ullian ME, Garnovskaya MN (2003) Bradyki$\operatorname{nin} \mathrm{B} 2$ receptor activates extracellular signal-regulated protein kinase in mIMCD-3 cells via epidermal growth factor receptor transactivation. J Pharmacol Exp Ther 304:968-977.

Naraba H, Ueno A, Kosugi Y, Yoshimura M, Murakami M, Kudo I, Oh-ishi S (1998) Agonist stimulation of B1 and B2 kinin receptors causes activation of the MAP kinase signaling pathway, resulting in the translocation of AP-1 in HEK 293 cells. FEBS Lett 435: 96-100.

Petho G, Derow A, Reeh PW (2001) Bradykinin-induced nociceptor sensitization to heat is mediated by cyclooxygenase products in isolated rat skin. Eur J Neurosci 14:210-218.

Polgár E, Campbell AD, MacIntyre LM, Watanabe M, Todd AJ (2007) Phosphorylation of ERK in neurokinin 1 receptor-expressing neurons in laminae III and IV of the rat spinal dorsal horn following noxious stimulation. Mol Pain 3:4.

Prado GN, Taylor L, Zhou X, Ricupero D, Mierke DF, Polgar P (2002) Mechanisms regulating the expression, self-maintenance, and signalingfunction of the bradykinin B2 and B1 receptors. J Cell Physiol 193:275-286.

Regan JW (2003) EP2 and EP4 prostanoid receptor signaling. Life Sci 74:143-153.

Samad TA, Moore KA, Sapirstein A, Billet S, Allchorne A, Poole S, Bonventre JV, Woolf CJ (2001) Interleukin-1-mediated induction of Cox-2 in the CNS contributes to inflammatory pain hypersensitivity. Nature 410:471-475.

Simone DA, Sorkin LS, Oh U, Chung JM, Owens CM, LaMotte RH, Willis WD (1991) Neurogenic hyperalgesia: central neural correlates in responses of spinothalamic tract neurons. J Neurophysiol 66:228-246.

Smith JA, Davis CL, Burgess GM (2000) Prostaglandin E2-induced sensitization of bradykinin-evoked responses in rat dorsal root ganglion neurons is mediated by cAMP-dependent protein kinase A. Eur J Neurosci 12:3250-3258.

Song I, Huganir RL (2002) Regulation of AMPA receptors during synaptic plasticity. Trends Neurosci 25:578-588.

Szerafin T, Erdei N, Fülöp T, Pasztor ET, Edes I, Koller A, Bagi Z (2006) Increased cyclooxygenase- 2 expression and prostaglandin-mediated dilation in coronary arterioles of patients with diabetes mellitus. Circ Res 99:e12-e17.

Tegeder I, Niederberger E, Vetter G, Brautigam L, Geisslinger G (2001) Effects of selective COX-1 and -2 inhibition on formalin-evoked nociceptive behaviour and prostaglandin $\mathrm{E}(2)$ release in the spinal cord. J Neurochem 79:777-786.

Wang H, Kohno T, Amaya F, Brenner GJ, Ito N, Allchorne A, Ji RR, Woolf CJ (2005) Bradykinin produces pain hypersensitivity by potentiating spinal cord glutamatergic synaptic transmission. J Neurosci 25:7986-7992.

Wang H, Ehnert C, Brenner GJ, Woolf CJ (2006) Bradykinin and peripheral sensitization. Biol Chem 387:11-14.

Woolf CJ (1983) Evidence for a central component of post-injury pain hypersensitivity. Nature 306:686-688.

Woolf CJ, Salter MW (2000) Neuronal plasticity-increasing the gain in pain. Science 288:1765-1768.

Xin WJ, Gong QJ, Xu JT, Yang HW, Zang Y, Zhang T, Li YY, Liu XG (2006) Role of phosphorylation of ERK in induction and maintenance of LTP of the C-fiber evoked field potentials in spinal dorsal horn. J Neurosci Res 84:934-943.

Yu J, Lubinsky D, Tsomaia N, Huang Z, Taylor L, Mierke D, Navarro J, Miraz O, Polgar P (2007) Activation of ERK, JNK, Akt, and G-protein coupled signaling by hybrid angiotensin II AT1/bradykinin B2 receptors expressed in HEK-293 cells. J Cell Biochem 101:192-204.

Yu XM, Askalan R, Keil II GJ, Salter MW (1997) NMDA channel regulation by channel-associated protein tyrosine kinase Src. Science 275:674-678. 